Portland State University

PDXScholar

$5-29-2017$

\title{
Comparing Infiltration Models to Estimate Infiltration Potential at Henry V Events
}

Rachel L. Wilson

Portland State University

Follow this and additional works at: https://pdxscholar.library.pdx.edu/honorstheses

Let us know how access to this document benefits you.

Recommended Citation

Wilson, Rachel L., "Comparing Infiltration Models to Estimate Infiltration Potential at Henry V Events" (2017). University Honors Theses. Paper 449.

https://doi.org/10.15760/honors.446

This Thesis is brought to you for free and open access. It has been accepted for inclusion in University Honors Theses by an authorized administrator of PDXScholar. Please contact us if we can make this document more accessible: pdxscholar@pdx.edu. 


\title{
COMPARING INFILTRATION MODELS TO ESTIMATE INFILTRATION POTENTIAL AT HENRY V EVENTS
}

\author{
by \\ Rachel Wilson \\ An undergraduate honors thesis submitted in partial fulfillment of the \\ requirements for the degree of \\ Bachelor of Science \\ in \\ University Honors \\ and \\ Environmental Engineering
}

Thesis Adviser

Dr. Annette Dietz

Portland State University 


\section{ABSTRACT}

It is useful to estimate infiltration rates and potentials for several reasons. Information about infiltration at a site may be to evaluate surface irrigation systems, to predict hydrologic conditions, and to solve many other problems (Ojha, et al., 2017). This thesis project is based on my engineering capstone project, which is to design a solution to control erosion in the soil bed adjacent to Henry $\mathrm{V}$ Events. There is erosion in the soil bed due to stormwater runoff from the roof, and due to the sloped soil bed which encourages the overland flow. The objective of this thesis is to estimate the infiltration rates and potentials at the site for a six year, four hour storm event using the Green-Ampt and Philip models. This will determine if only the soil bed slope can be changed to prevent erosion, or if soil bed improvements should ensue. The most conservative estimate was calculated using the Philip model and resulted in an infiltration rate of $0.77 \mathrm{~cm} / \mathrm{hr}$ and an infiltration potential of $4.27 \mathrm{~cm}$. This estimate determined that the soil would not be able to infiltrate the flow from the roof, and soil bed improvements will be recommended to Henry V Events. The soil suction head from the Green-Ampt model was estimated, as well as the length of the wetting front from the Philip model. A second analysis was performed using the infiltration models by varying the soil suction head and wetting front length for their respective models. The results showed how different soil suction heads and wetting front lengths change the infiltration rates and potentials for the four hour storm. There was a greater variability in the infiltration rates and potentials for both models with samples that had lower initial moisture contents.

\section{BASIS OF PROJECT}

As natural landscapes are being converted to urban ones, the amount of impervious surfaces increase and stormwater runoff becomes more significant as it is not able to infiltrate into soils and natural surfaces. Low impact development (LID) is an approach used in urban development that uses or mimics natural processes that result in the infiltration, evapotranspiration or use of stormwater in order to protect water quality and also reduce the quantity of stormwater for treatment (EPA, 2016). LID has been implemented more frequently in the past two decades and is recently starting to gain traction in research studies.

Portland State University invites local businesses to reach out for help with problems that senior undergraduate students assist with. These are called capstone projects and take place over the course of six months. The capstone group was assigned to a local firm called Henry V Events located in Portland, Oregon. Henry V Events is a full service communications agency specializing in live events and 
experiential marketing. Their building is LEED Silver certified and they take sustainability seriously. The building has been retrofitted with a bioswale that was originally designed to handle all the stormwater from the roof. Unfortunately, it is unable to handle the runoff from the roof during even moderately heavy rain events and water often flows out of outlets from the side of the building which will be referred to as "scuppers".

The flow from the scuppers poses a problem because it is causing erosion to the soil bed beneath. There are three scuppers in total located between 23 and 28 feet from the ground on the east side of the building. Because the water falls from such a great distance, the force it exerts on the soil when it reaches the ground is significant. The impact from the water creates a cavity in the soil and also carries the debris away via overland flow. The soil and debris get washed onto the adjacent sidewalk creating an unsightly agglomeration and a slippery pathway for pedestrians, making the sidewalk unsafe to walk on after recent rain events. The goal of the capstone project is to improve infiltration of water through the soil bed below the scuppers and prevent erosion and capture the rainwater to use as irrigation during the summer.

This thesis project will focus on estimating the infiltration capacity of the in-situ soil. The purpose of this is to evaluate if the soil is capable of handling the flow from the scuppers if it fell gently to the ground via rain chains and if the slope of the soil bed was flattened. This way our group can determine if low impact development of the soil, such as a French drain to provide infiltration or vegetation to provide soils stability, is necessary. If it is not required, implementing rain chains and flattening the soil bed may be sufficient. The Green-Ampt infiltration model and Philip infiltration model were used to evaluate the infiltration potential of site soil. The thesis will explore the variables used in these models, their assumptions, and predicting how well these models may reflect the actual infiltration capacities and potentials of the soil bed.

\section{INTRODUCTION TO INFILTRATION}

Infiltration into soil is the process of water flowing through the pores of a soil medium. It is a complex process that takes into account many variables. The process is gravity driven and is often aided by the suction and pressure forces that the soil exerts to help pull water from the surface of the soil deeper into the soil's profile.

A soil's infiltration rate refers to how well the soil can absorb water and has units of length per unit time. The hydraulic conductivity, initial moisture content, porosity, and soil composition all are 
factors that affect the infiltration rate. Hydraulic conductivity is the measure of the permeability of a soil, and describes the ease at which water can flow through the soil. It is also in units of length per unit time. Infiltration potential or infiltration capacity is the total amount of water that a soil column can hold during a given rain event in units of length. It is the integral of the infiltration rate.

Infiltration models are used to estimate the infiltration rates and infiltration potentials of soil. Different models are best applied to certain soil types and certain site conditions (Mazloom and Foladmand, 2013). The wide variety of sites and soil conditions makes it hard to determine what model will estimate the infiltration rate and infiltration capacity the best. Studies have been conducted on many diverse sites where infiltration rates were measured by simulated rainfall and hydrographs were made. With the data from the simulated rainfall and hydrographs, actual infiltration rates can be measured and compared to different models to see how well the models predicted the actual infiltration of the soil for a particular site. Simulated rainfall was out of the scope for this project so the models cannot be directly compared to what the actual infiltration rates at the site may be. Instead, this paper will mainly focus on comparing the infiltration rate and potential results between the Green-Ampt and Philip infiltration models, and how differences in initial moisture contents, hydraulic conductivity, suction head, and sorptivity may change the results for this site.

An intensity duration frequency analysis was performed for five years of precipitation data to estimate precipitation and runoff during a heavy storm at the site. With that information, the amount of water entering the soil bed can be estimated. Predicting the infiltration rate at this site will determine whether the soil can absorb the water from a heavy rain event with only flattening the slope of the soil bed since the slope is a factor contributing to the erosion in the soil bed. If the precipitation input exceeds the infiltration capacity, soil bed improvements will be recommended.

\section{INFILTRATION MODELS}

The infiltration models under examination in this paper are the Green-Ampt model and Philip Model. These models were chosen because they are based on empirical parameters. Empirical models are generally preferred over theoretical models because they reflect in-situ conditions. These models are based on key assumptions including a homogenous soil profile, and uniform movement of water through the soil column, and they predict infiltration rates for sandy soils more accurately than for clayey soils (Turner, 2006). These two models use slightly different parameters, which will be the basis for comparison for this thesis. 


\section{Green-Ampt model}

The Green-Ampt model is an infiltration model that accounts for many variables that reflect the soil's in-situ conditions. It is a function of saturated hydraulic conductivity, field and saturated moisture contents, soil suction head, and time. It is based on Richard's equation which describes the equality between the changing water content of the soil over time and the change in hydraulic conductivity and diffusivity through the depth of the soil profile (Putte, et al., 2013). The diffusivity is a variable related to the soil suction head term seen in the Green-Ampt model and the sorptivity term in the Philip model. These terms will be discussed in more depth in later paragraphs.

The Green-Ampt model considers a sharp wetting front that creates a suction head below the wetting front, encouraging the water above the wetting front to move down the soil profile. The general equation for the Green-Ampt infiltration rate $(f)$ is as follows:

$$
f=\frac{K_{S}\left(H_{o}+\psi_{f}+L_{f}\right)}{L_{f}} \quad \text { Equation } 1
$$

Where $K_{S}$ is the saturated hydraulic conductivity, $H_{o}$ is the ponding depth that creates a head above the soil, $\psi_{f}$ is the suction head below the wetting front, and $L_{f}$ is the length of the wetting front. Usually, the ponding depth is assumed to be zero since the ponding depth is usually too small to make a significant impact on the infiltration rate (Gupta, 2008). The equation can be manipulated to eliminate the length of the wetting front too since this variable is hard to measure. To do this, we can examine the corresponding infiltration capacity equation, which is the integral of Equation 1. The infiltration capacity $(F)$ is:

$$
F=\Delta \theta L_{f} \quad \text { Equation } 2
$$

Where $\Delta \theta$ is the difference between the saturated and field moisture contents. Rearranging, we can get an equation for infiltration rate that uses variables that are easier to measure.

$$
f=K_{s}+\frac{K_{s} \psi_{f} \Delta \theta}{F} \quad \text { Equation } 3
$$

However, before ponding occurs on the surface, we can assume that the infiltration rate is equal to precipitation. The infiltration potential before ponding can be described by: 


$$
F=i t \quad \text { Equation } 4
$$

Where $i$ is the precipitation and $t$ is the elapsed time since the start of the storm.

The infiltration capacity $\left(F_{p}\right)$ at the time of ponding can be calculated by the following equation:

$$
F_{p}=\frac{K_{s} \psi_{f} \Delta \theta}{i-K_{s}} \quad \text { Equation } 5
$$

Where $F_{p}$ is the infiltration capacity at the time of ponding. This formula is only valid exactly at the time of ponding and is valid when the precipitation rate is greater than the saturated hydraulic conductivity. The time of ponding can be calculated by:

$$
t_{p}=\frac{F_{p}}{i} \quad \text { Equation } 6
$$

Where $t_{p}$ is the time of ponding. Finding the time of ponding is useful because it defines when to apply equation 4, the infiltration potential before ponding, and when to apply equation 7 , the infiltration potential after ponding, as described below.

After ponding, the infiltration rate becomes a function of the infiltration potential. With the infiltration capacity (equation 2) and infiltration rate (equation 3), the length of the wetting front is still unknown so neither equation can be solved. Since $f=\frac{d F}{d t}$, the integration of equation 3 , assuming $F=0$ at $t=0$, and with some algebraic manipulation, provides a cumulative infiltration as follows (Gupta, 2008):

$$
K_{s} t=F-\psi_{f} \Delta \theta \ln \left(1+\frac{F}{\psi_{f} \Delta \theta}\right) \quad \text { Equation } 7
$$

Since $F$ cannot be solved directly, several values of $F$ need to be entered to find the time of the storm that the infiltration potential corresponds to. For example, if you would like to find the infiltration potential at 30 minutes, you must plug values of $F$ in until you get $t=30$ minutes.

If ponding conditions occurred after the start of the storm, a correction is usually applied to the infiltration potential after the ponding occurred. This is because the soil absorbs water differently if the surface is not fully saturated (Gupta, 2008). 


\section{Philip model}

The Philip model also uses Richard's equation as its basis (Philip, 1957). It has an infinite series solution that is a function of time. However, for simplification, the infinite series solution will be truncated to give us an approximation and is commonly shortened for this model (Jaynes and Gifford, 1981). It assumes initial ponded conditions where the ponding height does not change. The infiltration rate $(f)$ is described with the following equation:

$$
f=\frac{1}{2} S_{p} t^{-1 / 2}+C_{a} \quad \text { Equation } 8
$$

Where $C_{a}$ is the gravity factor and $S_{p}$ is the sorptivity. The infiltration potential $(F)$ can be calculated directly from integrating the infiltration rate.

$$
F=S_{p} t^{1 / 2}+C_{a} t \quad \text { Equation } 9
$$

For in-situ measurement of infiltration rates, the infiltration rate over time can yield the sorptivity and gravity factor variables by fitting the data to equation 6 (Mollerup, 2007). However, these variables were not calculated directly and need to be estimated from known variables. A comparison of the Philips two-term solution with the Green-Ampt equation suggests the following equation (Philip, 1957):

$$
C_{a}=2 / 3 K_{S} \quad \text { Equation } 10
$$

The sorptivity is a function of time and assumes that the soil gets less absorbent as the time of a rain event goes on. There are several ways to calculate the sorptivity using a variety of variables. The sorptivity equation that was used for this experiment is as follows (Youngs, 1968):

$$
S=\frac{\Delta \theta L_{f}}{t^{1 / 2}} \quad \text { Equation } 11
$$

This equation for sorptivity was chosen because it also has a basis on the Green-Ampt, and allows us to estimate the wetting front based on infiltration rates calculated from Green-Ampt in this experiment.

Generally, this form of the Philip model is valid for shorter time increments than other models because the first term in the equation collapses as time increases, so sorptivity becomes less of a factor 
in the infiltration rates and infiltration potentials (Mollerup, 2007). This will be taken into account during analysis.

\section{SITE}

The site is a soil bed adjacent to the building of Henry V Events located at 6360 NE Martin Luther King Jr. Boulevard in Portland, Oregon. A bioswale was implemented on the west side of the building designed to infiltrate a maximum of 1,300 gallons per day, which in theory would be more than enough to capture all of the rainwater flowing from the roof during heavy rain events. Unfortunately, pipes leading to the bioswales are easily clogged and heavy rain often causes the water to pond due to not being able to drain properly. This leads to overflow from the scuppers, which are on the east side of the building, directly above the soil bed of concern.

The soil bed is $249 \mathrm{ft}$ long and nine feet wide and is contained by the building's wall and sidewalks. Directly next to the building, there is a very slight slope, but the slope increases to about 25 degrees until it reaches the sidewalk, where there is no barrier to stop the soil from washing on the sidewalk. The three scuppers were designated $A, B$, and $C$ for this project as shown in Figure 1. Scupper $A$ is the furthest south and is approximately $23 \mathrm{ft}$ above the soil bed. Scupper B is the middle scupper and is approximately $25 \mathrm{ft}$ above the soil bed; it is located $89 \mathrm{ft}$ from Scupper A. Scupper $C$ is the furthest north and is approximately $28 \mathrm{ft}$ above the soil bed and $71 \mathrm{ft}$ from Scupper B. Soil samples A, B, and C were taken from the soil below their respective scupper. There are nine medium to large trees and several bushes in the bed. Only the middle scupper where soil sample B was taken had vegetation below it. A tree had been cut down near that location so there was significantly more organic debris in this area.

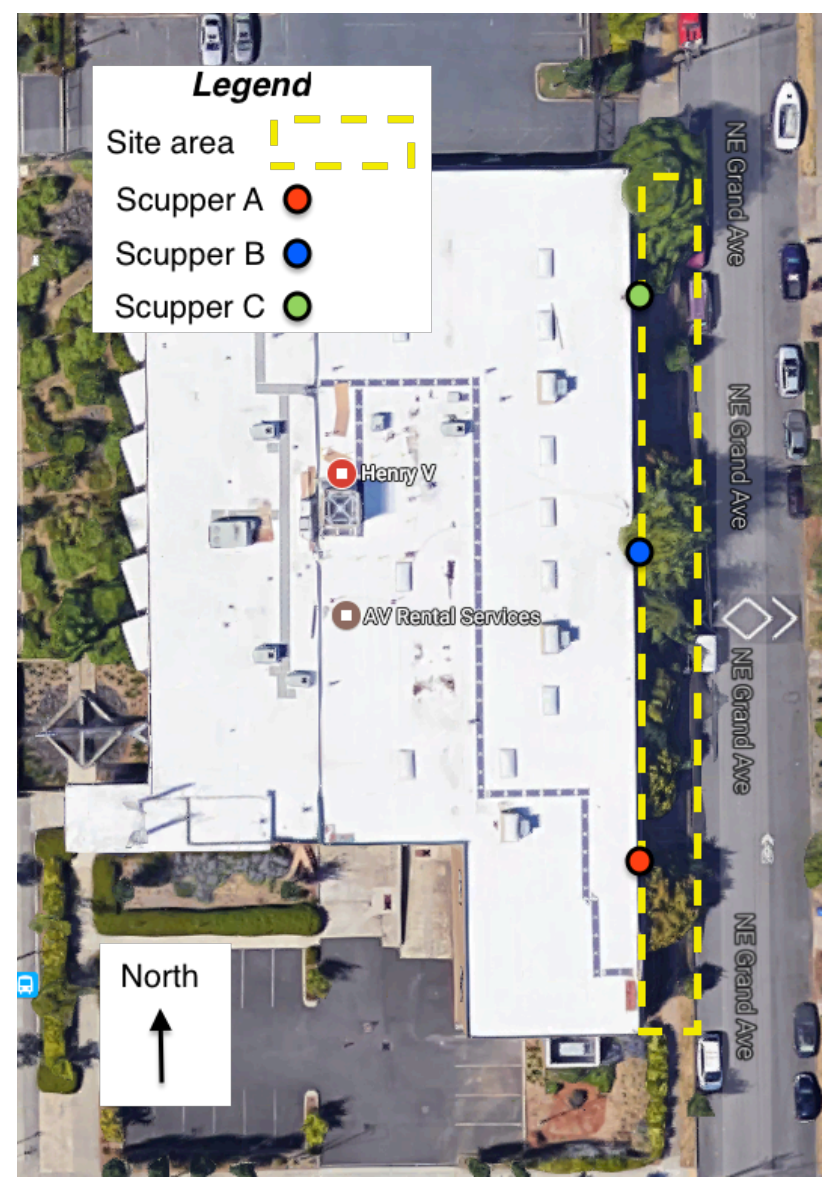

Figure 1: Ariel view of Henry V Events and outline of the area of interest. 


\section{METHODS}

One soil sample was collected from under each of the three scuppers to a depth of about six inches and approximately four liters of soil was taken from each location. The samples were taken after two mildly rainy days with a total of about 0.6 inches of rain. The soil was somewhat homogenous through the profile but had decaying organic matter in several spots as well as roots and some small stones. The soil was kept in plastic bags that were air tight until testing could begin.

The hydraulic conductivity was measured using a Darcy Apparatus, also known as a permeameter. Three permeameters were used for the three soil samples and prepared according to ASTM D2434, the constant head permeameter test. A sieve analysis was not performed, but the soils were examined and had mostly sand with some organic matter. The soil was confirmed to be mostly sandy from a geotechnical engineering instructor at Portland State University, so based on his experience, it is assumed that the soil would qualify for the test (Khosravifar, 2017).

The water content of the soils was measured according to ASTM D2216. The field water content was measured by first weighing the paper weigh boats containing the three samples. The soil samples were added to the weigh boats and weighed again. Next, the samples were microwaved until the soil was powdery and appeared to be completely dried. Their weights were measured again and the difference in the weight was calculated and resulted in the weight of the water that had evaporated from the soil. The saturated water content was measured the same way, except the soil was saturated rather than only containing the field moisture content. The soil was saturated by adding water to the soil until the soil could flow, but not saturated to the point where water was ponding on the sample.

To predict the amount of precipitation that will happen during a rain event, five years of precipitation data from the National Weather Service Forecast Archive was accessed and the heaviest rain event was found during those five years. Five years of data was available, so the rain event is considered to be a six year storm from an intensity duration frequency analysis. For simplicity, the total rain for that day was summed and assumed that that amount of precipitation happened over a four hour period for a worst case scenario solution. The amount of precipitation that the soil bed receives includes the precipitation amount and also flow from the roof. To account for this, the area of roof was multiplied by the depth of water falling over that time period to yield the volume of water that would fall on the roof during a six year storm event. A bioswale handles most of this water but there is no data and no way to predict how much water the bioswale can actually handle. The capstone group decided that a conservative estimate for the amount of water that the bioswale can handle during a heavy rain event is two thirds of the water that falls on the roof. This means that the scuppers discharge one third 
of the water. Using that information and the area of the soil bed, a "precipitation" of approximately 9.8 $\mathrm{cm} / \mathrm{hr}$ is estimated to impact the soil bed for four hours during a six-year storm.

The calculations for the Green-Ampt and Philip models were performed on Excel. To calculate the infiltration rates and infiltration potentials, the Green-Ampt model was used first since all necessary variables had been collected besides the soil suction head. The soil suction head was estimated based on the Clapp and Hornberger parameters for equations based on analysis of 1845 soils (Clapp and Hornberger, 1978). The parameters required to use the relationship from this study include the type of soil, the hydraulic conductivity, and saturated and initial moisture contents. From a table based on the Clapp and Hornberger analysis, the soil suction head was estimated for each soil sample (see values in Table 1).

Since a correction is useful to use for the Green-Ampt model to ensure the results are as accurate as possible, the time of ponding was calculated for each sample using equation 6 . Equation 4 was used to find the infiltration capacity before ponding, and equation 7 was used to find infiltration capacity after ponding. Before equation 7 could be used, time increments were selected to define the times that the infiltration capacities and thus infiltration rates should be calculated for. In this experiment, time increments of 0.25 hours were chosen and ranged from 0 to 4 hours to represent the time of the storm.

Next, infiltration capacities were found for the selected time increments. To start this process, a list of values that represented a range of infiltration capacities were made in Excel for each sample. The infiltration capacities varied from 6 to $32 \mathrm{~cm}$ for sample A, 1 to $11 \mathrm{~cm}$ for sample B, and 2 to $22 \mathrm{~cm}$ for sample $C$ and were in increments of $1 \mathrm{~cm}$. These values were based on trial and error using equation 7 and adjusted accordingly based on the resulting times. The infiltration capacities should be chosen so that the first time calculated from equation 7 is before the first time increment that was selected, and the last time calculated is after the last time increment (i.e. 4 hours). Equation 7 was applied to each of the infiltration capacities in the list to reveal a relationship between the time and infiltration capacity. A linear relationship is assumed between the time increments and corresponding infiltration capacities. Linear interpolation was used to find the infiltration capacity of interest. Please refer to Hydrology and Hydraulic Systems (Gupta, 2008) to see detailed instructions for performing these calculations. After the infiltration capacities had been found, the infiltration rates could be calculated from equation 3 .

To use the Philip model, the length of the wetting front must be known. This parameter was not measured in this experiment. The Green-Ampt model used a soil suction head term that was not measured in this experiment but could be estimated based on the Clapp and Hornberger relationships. 
Unlike the soil suction head, the length of wetting front is extremely variable, is less dependent on the soil properties, and there is no equation based on parameters gathered in this experiment to estimate it (Mollerup, 2007). To estimate the wetting front, an assumption was made that at the time of ponding, the infiltration rates of the Green-Ampt and Philip models are the same. This assumption can be made because the Philip model is most accurate early in the storm. Since the Green-Ampt correction was applied to account for ponding, we can also assume that the infiltration rate is accurate if the parameters used in the analysis are accurate. The best time to assume the Green-Ampt and Philip model infiltration rates are equal is therefore at the time of ponding. Using this method also created a way to compare the Green-Ampt and Philip models throughout the duration of the storm. Since they both have the same infiltration rate at the time of ponding, it is useful to see how the two models vary after that time. The sorptivity term was calculated using equation 8 , the infiltration rate and equation 11 . Using the sorptivity and the time of ponding, the length of the wetting front was estimated for each sample. For simplicity, the length of the wetting front was assumed not to change when calculating the infiltration rates and capacities from 0 to 4 hours of the storm.

To calculate the infiltration potential, first the gravity constant was calculated using equation 10 . A list was made in Excel representing time values that ranged from 0.25 to 4 hours and were in increments of 0.25 hours, just as was done when performing calculations for the Green-Ampt model. Sorptivity terms for each time increment were calculated based on equation 11 . The infiltration potentials and infiltration rates were easily calculated using equations 9 and 8, respectively.

Each infiltration model is subject to uncertainty based on the assumptions that were made about the variables. For the Green-Ampt model, that variable was the soil suction head. For the Philip model, that variable was the length of the wetting front and thus the sorptivity term. To examine how variations of these terms may have an impact on the infiltration rates and capacities, a second analysis of the models were performed. The Green-Ampt model was applied for the design storm using several different values for the soil suction head for each sample. Next, the Philip model was applied similarly but using several different values for the wetting from lengths for each sample. Each calculation was performed at four hours into the storm for consistency and provided a worst case scenario for infiltration rates.

To use the Green-Ampt model to examine variations in the soil suction head, five soil suction heads were chosen and applied to equation 7 to find the infiltration potential, and then equation 3 to find the infiltration rate. These equations were used since four hours is after the time of ponding and the calculations needed the corrected equations. The soil suction heads that were chosen were 
somewhat arbitrary and each were in increments of five ranging over $40 \mathrm{~cm}$. The values of the soil suction heads that were estimated based on the Clapp and Hornberger parameters were rounded to the nearest $5 \mathrm{~cm}$, and that value was selected as the median in the series of five soil suction heads. The purpose for doing this is to see how the infiltration rate and capacity change based on changing soil suction heads at both higher and lower values than the estimated soil suction head. The selection of soil suction heads was somewhat arbitrary because this term is variable to begin with, and chances are the exact soil suction head value would not be chosen correctly from the Clapp and Hornberger parameters. Instead, a test would need to be performed to measure these values. Each sample's infiltration rate and capacity were calculated over a soil suction head range of $40 \mathrm{~cm}$ to see how variable the infiltration rates and capacities were. By using the same variations in soil suction head, the results could be compared more easily.

To use the Philip model to examine variations in wetting front lengths, a similar arbitrary method to choosing soil suction heads was used for selecting wetting front lengths. Ten lengths were chosen, and the fifth length was made equal to the wetting front length value calculated from comparing the Green-Ampt and Philip model's time of ponding infiltration rates. Sample A had a wetting front length initially calculated that was larger than sample B and C. From this information, it is assumed that it would most likely vary the most since water can travel more easily through sandy soils. Sample $A^{\prime}$ 's wetting front lengths ranged in increments of four from $2 \mathrm{~cm}$ to $38 \mathrm{~cm}$. Samples $B$ and $C$ had wetting front lengths that varied from $1 \mathrm{~cm}$ to $18 \mathrm{~cm}$, and $3 \mathrm{~cm}$ to $30 \mathrm{~cm}$, respectively. These values were chosen to see how wetting front lengths shorter or longer than the estimated length may change infiltration rate and capacity. An extensive range was chosen to see how widely the infiltrations rates and capacities may change.

\section{RESULTS}

Sample A was the sandiest sample with many thin roots throughout the four liter sample. There was some organic matter, but the sand was coarse and seemed to have a wide grain size distribution with bits of smooth stone in the mixture. Sample B contained some sand but had much more organic material including thicker roots, decaying bark, and decaying leaves. This was due to the tree that had been taken down near that area, and due to the nearby vegetation. The grain size distribution appeared to be smaller with fewer stones than sample A. Sample C was very similar in texture to sample $A$ but had some decaying bark throughout the mixture similar to the bark in sample B. 
Each of the samples varied in hydraulic conductivity, but were all within an order of magnitude. Sample A had the most permeable soil with a hydraulic conductivity of $4.2 \mathrm{~cm} / \mathrm{hr}$. Sample B and C had lower hydraulic conductivities equal to $0.71 \mathrm{~cm} / \mathrm{hr}$ and $2.1 \mathrm{~cm} / \mathrm{hr}$, respectively. Sample B had a very high initial moisture content of $30 \%$, and a saturated moisture content of $59.7 \%$. Both the saturated and initial moisture contents were much higher than those of samples A and C. Samples A and C had much lower initial moisture contents of $5.5 \%$ and $7.2 \%$, respectively. This suggests that the soil could drain more easily than sample $B$, hence the higher hydraulic conductivities of samples $A$ and $C$.

Table 1: Raw data from experiments and estimates.

\begin{tabular}{|c|r|r|r|}
\hline $\begin{array}{c}\text { Hydraulic } \\
\text { conductivity (cm/hr) }\end{array}$ & Sample A & Sample B & \multicolumn{1}{|c|}{ Sample C } \\
\hline $\begin{array}{c}\text { Saturated moisture } \\
\text { content, } \theta \text { s (\%) }\end{array}$ & 0.2138 & 0.7105 & 2.111 \\
\hline $\begin{array}{c}\text { Initial moisture } \\
\text { content, } \theta i(\%)\end{array}$ & 0.0555 & 0.5969 & 0.4585 \\
\hline $\begin{array}{c}\text { Soil suction head, } \Psi \\
(\mathrm{cm})\end{array}$ & 29.9 & 0.3 & 0.07272 \\
\hline $\begin{array}{c}\text { Length of wetting } \\
\text { front, } \mathrm{L}_{\mathrm{f}}(\mathrm{cm})\end{array}$ & 19 & 48.1 & 32.5 \\
\hline
\end{tabular}

Tables 2 through 4 show the infiltration potentials and infiltration rates for each sample during the duration of the four hour storm. The sorptivity values used in the Philip model calculated using equation 11 have been added to Tables 2 through 4 to show how the sorptivity values change over time. Figures 2 and 3 are the infiltration capacity curves and provide a visual for how the infiltration rates decrease over time for the two models. They were plotted using the data from Tables 2 through 4 . The infiltration capacities are the areas, or integrals, under each curve. 
Table 2: Infiltration rates and potentials from the Green-Ampt and Philip models for sample A.

\begin{tabular}{|c|r|r||r|r|r|}
\cline { 2 - 5 } \multicolumn{1}{l|}{} & \multicolumn{2}{c||}{ GREEN-AMPT } & \multicolumn{3}{c|}{ PHILIP } \\
\hline Time $(\mathrm{hrs})$ & $\mathrm{F}(\mathrm{cm})$ & $\mathrm{f}(\mathrm{cm} / \mathrm{hr})$ & $\mathrm{S}\left(\mathrm{cm} / \mathrm{hr}^{1 / 2}\right)$ & $\mathrm{F}(\mathrm{cm})$ & $\mathrm{f}(\mathrm{cm} / \mathrm{hr})$ \\
\hline 0.25 & 5.79556 & 13.2813 & 15.8498 & 8.62720 & 18.6590 \\
\hline 0.5 & 8.69871 & 10.2551 & 11.2075 & 9.32950 & 10.7341 \\
\hline 1 & 9.78390 & 9.58506 & 7.9249 & 10.7341 & 6.77166 \\
\hline 1.5 & 14.1090 & 7.93851 & 6.47065 & 12.1387 & 5.45084 \\
\hline 2 & 17.8637 & 7.15563 & 5.60375 & 13.5433 & 4.79043 \\
\hline 2.5 & 21.3090 & 6.67999 & 5.01214 & 14.9479 & 4.39419 \\
\hline 3 & 24.564 & 6.3531 & 4.5754 & 16.352 & 4.1300 \\
\hline 3.5 & 27.680 & 6.1123 & 4.2360 & 17.757 & 3.9413 \\
\hline 4 & 30.687 & 5.9263 & 3.9624 & 19.161 & 3.7998 \\
\hline
\end{tabular}

Table 3: Infiltration rates and potentials from the Green-Ampt and Philip models for sample B.

\begin{tabular}{|c|r|r||r|r|r|}
\cline { 2 - 5 } \multicolumn{1}{l|}{} & \multicolumn{2}{c||}{ GREEN-AMPT } & \multicolumn{3}{c|}{ PHILIP } \\
\hline Time $(\mathrm{hrs})$ & $\mathrm{F}(\mathrm{cm})$ & $\mathrm{f}(\mathrm{cm} / \mathrm{hr})$ & $\mathrm{S}\left(\mathrm{cm} / \mathrm{hr}^{1 / 2}\right)$ & $\mathrm{F}(\mathrm{cm})$ & $\mathrm{f}(\mathrm{cm} / \mathrm{hr})$ \\
\hline 0.25 & 2.06587 & 5.61238 & 4.7504 & 2.49362 & 5.22411 \\
\hline 0.5 & 3.19530 & 3.87975 & 3.35904 & 2.61205 & 2.84891 \\
\hline 1 & 4.82065 & 2.81122 & 2.3752 & 2.84891 & 1.66131 \\
\hline 1.5 & 6.10848 & 2.36834 & 1.93934 & 3.08577 & 1.26544 \\
\hline 2 & 7.22092 & 2.11295 & 1.67952 & 3.32263 & 1.06751 \\
\hline 2.5 & 8.23224 & 1.94067 & 1.50220 & 3.55948 & 0.94875 \\
\hline 3 & 9.17136 & 1.81471 & 1.37132 & 3.79634 & 0.86958 \\
\hline 3.5 & 10.0571 & 1.71746 & 1.26959 & 4.03320 & 0.81302 \\
\hline 4 & 10.8954 & 1.63999 & 1.1876 & 4.27006 & 0.77061 \\
\hline
\end{tabular}


Table 4: Infiltration rates and potentials from the Green-Ampt and Philip models for sample C.

\begin{tabular}{|c|r|r||r|r|r|}
\cline { 2 - 6 } \multicolumn{1}{l|}{} & \multicolumn{2}{c||}{ GREEN-AMPT } & \multicolumn{2}{c|}{ PHILIP } \\
\hline Time $(\mathrm{hrs})$ & $\mathrm{F}(\mathrm{cm})$ & $\mathrm{f}(\mathrm{cm} / \mathrm{hr})$ & $\mathrm{S}\left(\mathrm{cm} / \mathrm{hr}^{1 / 2}\right)$ & $\mathrm{F}(\mathrm{cm})$ & $\mathrm{f}(\mathrm{cm} / \mathrm{hr})$ \\
\hline 0.25 & 2.22177 & 14.0238 & 11.5734 & 6.13853 & 7.9807 \\
\hline 0.5 & 4.65561 & 7.79610 & 8.18362 & 6.49037 & 4.30069 \\
\hline 1 & 7.88212 & 5.46893 & 5.7867 & 7.19404 & 3.33624 \\
\hline 1.5 & 10.3820 & 4.66036 & 4.72482 & 7.89771 & 2.85401 \\
\hline 2 & 12.5894 & 4.21337 & 4.09181 & 8.60138 & 2.56468 \\
\hline 2.5 & 14.6204 & 3.92132 & 3.65983 & 9.30505 & 2.37179 \\
\hline 3 & 16.5289 & 3.71230 & 3.34095 & 10.0087 & 2.23401 \\
\hline 3.5 & 18.3471 & 3.55361 & 3.09312 & 10.7124 & 2.13068 \\
\hline 4 & 20.0958 & 3.42808 & 2.89335 & 11.4160 & \\
\hline
\end{tabular}

The soil suction head varies with different soils and water contents. To demonstrate how the infiltration rates and capacities may change for each sample, a soil suction head range of $40 \mathrm{~cm}$ was applied at hour four of the storm for each sample. The median soil suction head in the range represents the estimated soil suction head rounded to the nearest fifth integer. Table 5 shows the infiltration rates and potentials at the end of the four hour storm for various suction heads representing possible ranges for soil samples A, B, and C.

Table 5: Infiltration rates and potential using the Green-Ampt model for wide ranges of soil suction head for each soil at hour four of the storm.

\begin{tabular}{|c|l|l||l|l|l|||c|l|l|}
\hline \multicolumn{5}{|l||}{ Sample A Sample B } & \multicolumn{2}{|l|}{ Sample C } \\
\hline$\Psi$ & $F(\mathrm{~cm})$ & $\mathrm{f}(\mathrm{cm} / \mathrm{hr})$ & $\Psi$ & $F(\mathrm{~cm})$ & $\mathrm{f}(\mathrm{cm} / \mathrm{hr})$ & $\Psi$ & $F(\mathrm{~cm})$ & $\mathrm{f}(\mathrm{cm} / \mathrm{hr})$ \\
\hline 10 & 24.962 & 4.918 & 25 & 8.344 & 1.343 & 15 & 16.124 & 2.869 \\
\hline 20 & 29.451 & 5.407 & 35 & 9.633 & 1.477 & 25 & 18.872 & 3.190 \\
\hline 30 & 32.992 & 5.812 & 45 & 10.638 & 1.603 & 35 & 21.144 & 3.459 \\
\hline 40 & 36.040 & 6.164 & 55 & 11.488 & 1.721 & 45 & 23.102 & 3.697 \\
\hline 50 & 38.737 & 6.482 & 65 & 12.296 & 1.826 & 55 & 24.927 & 3.908 \\
\hline
\end{tabular}


The length of the wetting front is a variable that cannot be estimated accurately using the variables gathered in this experiment. To examine a variation of wetting front lengths and subsequently the soil sorptivity term, several wetting front lengths were used to calculate the infiltration potential at the end of a 4 hour storm. Table 6 shows the wetting front lengths and infiltration rates and potentials for soil samples A, B, and C.

Table 6: Infiltration potential calculated using the Philip model and sorptivity values for wide ranges of wetting front lengths for each soil at hour four of the storm.

\begin{tabular}{|c|c|c|c|c|c|c|c|c|c|c|c|}
\hline \multicolumn{4}{|c|}{ Sample A } & \multicolumn{4}{|c|}{ Sample B } & \multicolumn{4}{|c|}{ Sample C } \\
\hline $\operatorname{Lf}(\mathrm{cm})$ & $\mathrm{S}\left(\mathrm{cm} / \mathrm{hr}^{1 / 2}\right)$ & $F(\mathrm{~cm})$ & $\mathrm{f}(\mathrm{cm} / \mathrm{hr})$ & $\operatorname{Lf}(\mathrm{cm})$ & $\mathrm{S}\left(\mathrm{cm} / \mathrm{hr}^{1 / 2}\right)$ & $F(\mathrm{~cm})$ & $\mathrm{f}(\mathrm{cm} / \mathrm{hr})$ & Lf $(\mathrm{cm})$ & $\mathrm{S}\left(\mathrm{cm} / \mathrm{hr}^{1 / 2}\right)$ & $\mathrm{F}(\mathrm{cm})$ & $\mathrm{f}(\mathrm{cm} / \mathrm{hr})$ \\
\hline 4 & 0.834 & 12.905 & 3.018 & 1 & 0.149 & 2.192 & 0.511 & 3 & 0.579 & 6.787 & 1.552 \\
\hline 7 & 1.460 & 14.157 & 3.174 & 2 & 0.297 & 2.489 & 0.548 & 6 & 1.157 & 7.944 & 1.697 \\
\hline 11 & 2.294 & 15.825 & 3.383 & 4 & 0.594 & 3.083 & 0.622 & 9 & 1.736 & 9.101 & 1.841 \\
\hline 15 & 3.128 & 17.493 & 3.591 & 6 & 0.891 & 3.676 & 0.696 & 12 & 2.315 & 10.259 & 1.986 \\
\hline 19 & 3.962 & 19.162 & 3.800 & 8 & 1.188 & 4.270 & 0.771 & 15 & 2.893 & 11.416 & 2.131 \\
\hline 23 & 4.797 & 20.830 & 4.008 & 10 & 1.485 & 4.864 & 0.845 & 18 & 3.472 & 12.573 & 2.275 \\
\hline 27 & 5.631 & 22.499 & 4.217 & 12 & 1.781 & 5.458 & 0.919 & 21 & 4.051 & 13.731 & 2.420 \\
\hline 31 & 6.465 & 24.167 & 4.425 & 14 & 2.078 & 6.052 & 0.993 & 24 & 4.629 & 14.888 & 2.565 \\
\hline 35 & 7.299 & 25.835 & 4.634 & 16 & 2.375 & 6.645 & 1.068 & 27 & 5.208 & 16.045 & 2.709 \\
\hline 39 & 8.133 & 27.504 & 4.843 & 18 & 2.672 & 7.239 & 1.142 & 30 & 5.787 & 17.203 & 2.854 \\
\hline
\end{tabular}




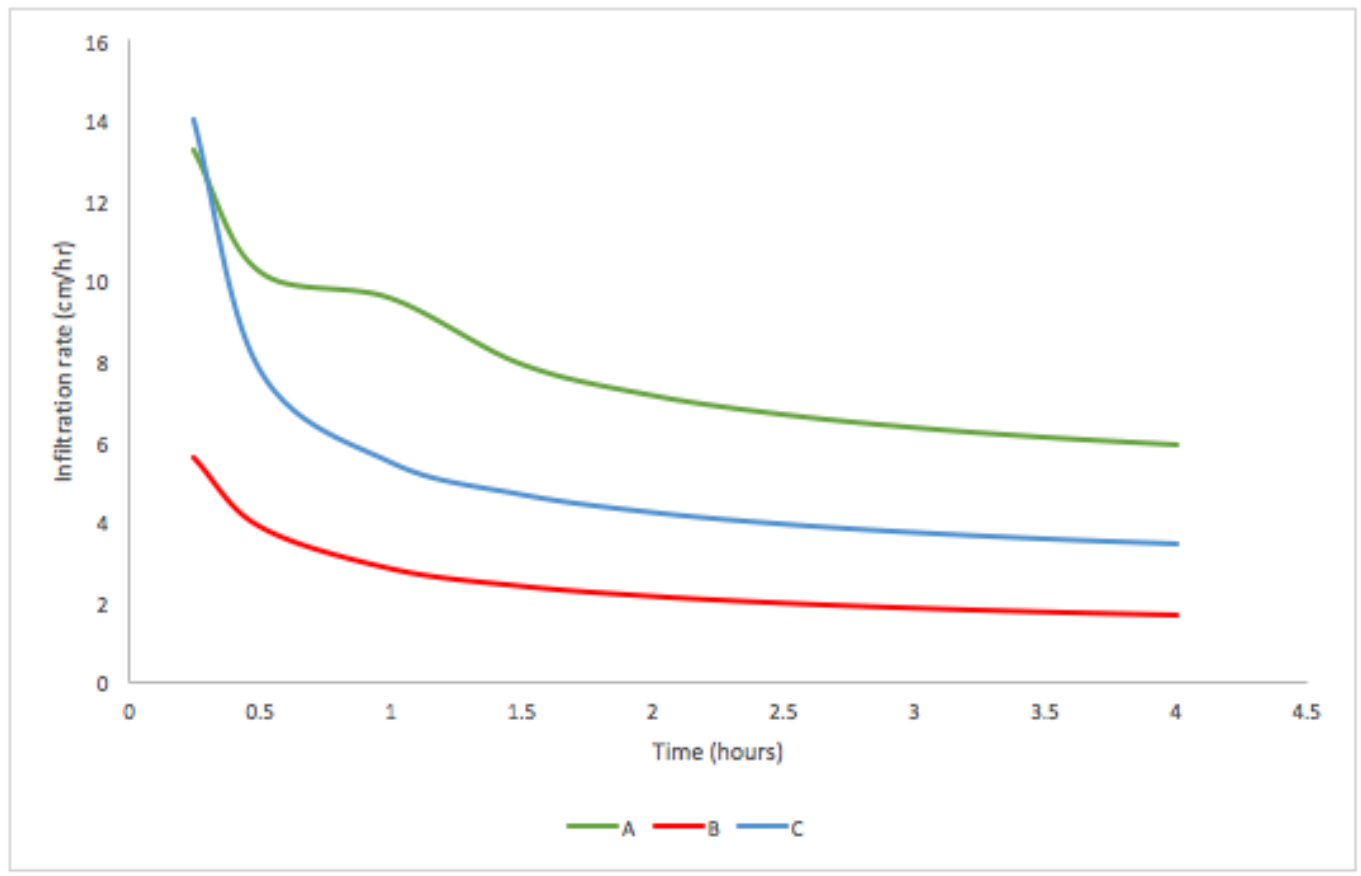

Figure 2: Infiltration rate vs. time using the Green-Ampt model for three soil samples.

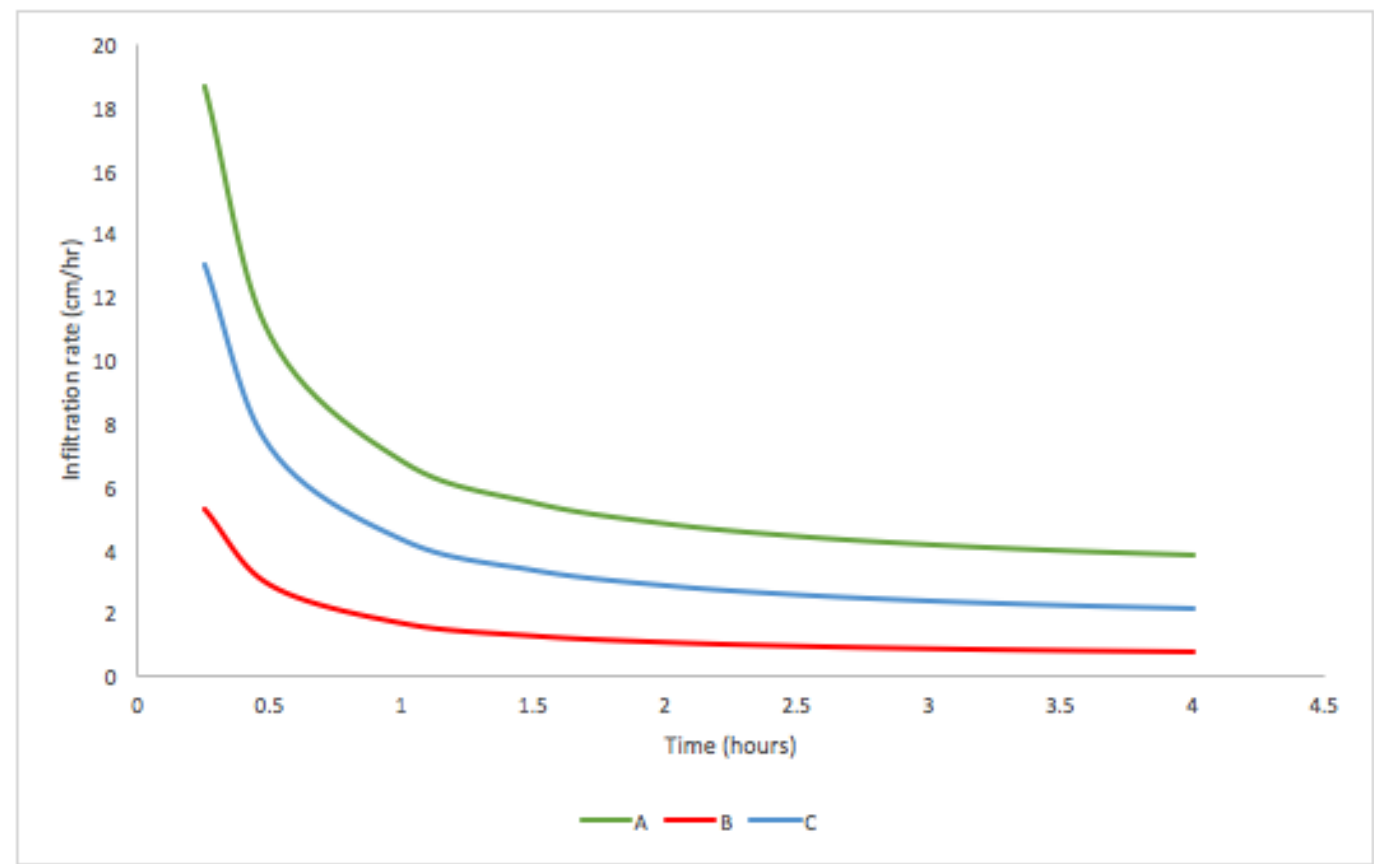

Figure 3: Infiltration rate vs. time using the Philip model. 


\section{DISCUSSION}

The soil samples collected for this experiment were not as homogenous as samples should be to classify them correctly. Classifying the soils is useful to be able to compare them to typical infiltration rates and typical hydraulic conductivities. Because the samples were somewhat heterogeneous, it is not clear exactly what class of soil they belong in. However, the samples did appear to be mostly composed of sand combined with loam and a few coarse rocks. Sample B had the most loam, and soil sample A had the most sand.

Typical infiltration rates for loamy sand are about $5 \mathrm{~cm} / \mathrm{hr}$. For sandy loam, a similar soil composition but consisting of a greater percentage of loam, typical infiltration rates are around 2.5 $\mathrm{cm} / \mathrm{hr}$. For loam, infiltration rates are estimated to be $1.27 \mathrm{~cm} / \mathrm{hr}$ (ASCE, 1998). The initial infiltration rates were very high using the Green-Ampt model and Philip compared to typical values. As the soil became more saturated through the duration of the storm, the infiltration rates fell into typical ranges.

The hydraulic conductivities measured from the permeameter tests were within the range for typical loamy/sandy soils. For loam soils, hydraulic conductivity ranges between 0.417 to $4.17 \mathrm{~cm} / \mathrm{hr}$. For fine and medium grain sandy soils, hydraulic conductivities can range between 4.17 to $83.33 \mathrm{~cm} / \mathrm{hr}$ (Guideal, et al., 2011). However, hydraulic conductivities are generally on the lower end of this spectrum for sandy soils. The hydraulic conductivities calculated in this experiment show that sample A had a higher hydraulic conductivity likely due to containing a higher percentage of sand. Samples B and $\mathrm{C}$ fall in the range for loamier soils, and they did have a greater percentage of organic and decaying material.

A reason that the infiltration rates were relatively high in the first two to three hours of the storm is that there was a large difference between the saturated and field moisture contents. The moisture contents in the soil samples were low for samples A and C, with the lowest being $5.5 \%$. Soil that is a host to plants preferably has a moisture content around $20 \%$ to keep the plants healthy, so it is surprising that the moisture contents of samples A and C were so low (Jaynes and Gifford, 1981). There had been rain on and off for two days prior to sampling, but very little rain the week before that. There is a chance that some of the water in the soil samples may have evaporated due to the bags not being sealed tight enough while they waited to be tested. Lower initial infiltration rates and thus lower infiltration potentials would have been calculated if there were a higher initial moisture content.

Both models resulted in high infiltration rates for samples $A$ and $C$ at the start of the storm, likely due to their low initial moisture contents. The Green-Ampt model showed a more gradual decline in infiltration rates, especially for sample, A which was around $10 \mathrm{~cm} / \mathrm{hr}$ for the first hour of the storm. 
This was in part due to the time of ponding. The infiltration rate generally falls less rapidly directly after the time of ponding because there is less air in the pores of the soil and the pores conduct water more efficiently. The results from the Philip model showed that the infiltration rate decreased exponentially soon after the storm. Exponential decreases in infiltration rates usually happen early in a storm. It depends on the storm, but generally in the first hour or so (Turner, 2006). Although both models have uncertainty, the Philip resulted in an infiltration capacity curve more similar to typical infiltration capacity curves.

The rate at which the infiltration capacity curve declines affects the amount of water that the soil can hold, or the infiltration capacity. Although both models resulted in infiltration rates within normal ranges during some time periods, and both models have the same general shape, their infiltration capacities are very different. Sample A had an infiltration potential of $30.7 \mathrm{~cm}$ at the end of the four hour storm using the Green-Ampt model, and had an infiltration potential of $19.2 \mathrm{~cm}$ using the Philip model. Similar trends were found in the other samples. Both models have uncertainty, but the Philip model has a more conservative approach, which is generally better to use when reporting infiltration capacities.

The Green-Ampt model would have been more accurate in predicting the infiltration rates and potentials if the soil suction head was known. There are many ways to measure soil suction but the experimentation required was out of the scope of this project. However, the effect of suction head variation was explored by using a range of plausible soil suction heads for each soil (Table 5).Sample B's infiltration rate varied the least with values between $1.34 \mathrm{~cm} / \mathrm{hr}$ and $1.83 \mathrm{~cm} / \mathrm{hr}$ with soil suction ranging from $25 \mathrm{~cm}$ and $65 \mathrm{~cm}$, respectively. These infiltration rates are more common for "garden soils" that contain a significant amount of organic material. Another reason that sample B had lower infiltration rates is because sample $B$ had the highest initial moisture content, decreasing the difference between the saturated and field moisture contents. Sample A's infiltration rate varied the most from 4.9 $\mathrm{cm} / \mathrm{hr}$ with a soil suction head of $10 \mathrm{~cm}$ and $6.5 \mathrm{~cm} / \mathrm{hr}$ with a soil suction head of $50 \mathrm{~cm}$. This difference in range in soil suction head is the same as the range for sample B, but sample A used larger values for the soil suction heads.

Sample A had the greatest difference between initial and saturated moisture contents, which is another reason for the wider range of infiltration rates and thus potentials. Comparing the data where the soil suction heads for A and B were similar, it is evident the infiltration rate in sample A was still much higher than sample B. This demonstrates how much initial moisture content can change the infiltration rates. If a soil is dry, it craves moisture and absorbs it like a sponge. If it is already saturated, 
the infiltration rate and thus infiltration potential is much smaller. The results from samples $A$ and $B$ show that if a soil is well saturated, the soil suction head will have less of an impact on the variation of infiltration rates and potentials.

There was a sharp decline in the infiltration rate for the Philip model because the infiltration rate decreases rapidly due to the time variable in the first term of equation 8. Using only two terms for the Philip model instead of the infinite series solutions means that the infiltration rate will approach the hydraulic conductivity over a certain period of time, and will eventually become negative over very long periods of time. Infiltration rates tend to asymptotically approach the saturated hydraulic conductivity after long periods of infiltration (Warrick and Nielsen, 1980). However, infiltration rates should never actually reach the saturated hydraulic conductivity since there will always be some air trapped in the soil, meaning that the flow in the soil is not perfectly saturated (Ojha, et al., 2017). Sample A was the only sample that had an infiltration rate go below the hydraulic conductivity. Samples B and C started to approach their respective hydraulic conductivities at four hours, indicating that the storm's time period worked well for those samples. Sample A's hydraulic conductivity was approached at about 2.5 hours. Soils with larger differences in saturated and initial moisture contents, higher hydraulic conductivities, and longer lengths of wetting front will be valid for shorter periods of time, which is what was seen by comparing these samples.

The Philip model results are uncertain because of the use of the best-guessed wetting front length. The wetting front length was based on the infiltration rate being equal to the infiltration rate using the Green-Ampt model at the time of ponding. Making those infiltration rates at the time of ponding equal yielded the wetting front length for the Philip model. This method was used because the Philip model assumes ponding conditions. The general form of the Green-Ampt model also assumes ponding conditions, but a correction was applied so that if the time of ponding is known, the assumption does not need to hold for the duration of the storm. For samples $A$ and $C$, the time of ponding was not until about one hour and one half hour after the start of the storm, respectively. However, the infiltration rates and potentials before the time of ponding using the Philip model may not be as accurate.

The wetting front lengths that were calculated from the Green-Ampt model yielded results that seemed reasonable and made sense for each sample individually. These results provided some validity for the Green-Ampt model for these soils samples and thus the Philip model. However, that does not mean that the results were accurate, but were within reasonable ranges (ASCE, 1998). Table 6 shows several wetting front lengths for each sample to see how the wetting front length affects the soil's 
sorptivity, the infiltration rate, and infiltration potential. Sample A was calculated with wetting front lengths over a wider range since sandier soils can typically have longer wetting fronts, but can also be short like clayey soils depending on factors such as how recently a rain event occurred, initial moisture contents, etc. Because of the wider range of wetting front lengths, the infiltration rates and potentials ranged more vastly than the other samples. The original calculation for sample A had a wetting front length of $19 \mathrm{~cm}$, although if the infiltration rate was calculated with a shorter wetting front, the results would have been closer to typical measurements of infiltration rates. Sample B showed the most plausible infiltration rates from $0.51 \mathrm{~cm} / \mathrm{hr}$ to $1.07 \mathrm{~cm} / \mathrm{hr}$ calculated with wetting front lengths ranging from $1 \mathrm{~cm}-16 \mathrm{~cm}$, respectively. Sample B was assumed to have shorter wetting front lengths because organic material tends to hold on to moisture and does not drain through the soil as easily.

When computing infiltration rates, a conservative approach should always be used. Usually the measured hydraulic conductivity is decreased by a factor of 2 - 4 as a factor of safety to yield conservative results. This was not done for this experiment and may have resulted in overestimating the infiltration rates and potentials. The infiltration rates, especially for sample A, probably would have been more accurate if a conservative hydraulic conductivity was used.

Another method that could have been used to yield results that are more realistic would have been to measure the field moisture contents as soon as possible after collection. The initial moisture contents for samples $\mathrm{A}$ and $\mathrm{C}$ were very low, and this affected the results for both models. The infiltration rates and potentials for samples $A$ and $C$ were much higher than sample $B$, likely due to the initial moisture contents. Both models were a function of the saturated and initial moisture contents. The moisture contents are directly used for calculating the infiltration rate and potential for the GreenAmpt model, and was applied to find the soil suction head using Clapp and Hornberger relationship. The difference in initial and saturated moisture contents are a function of sorptivity for the Philip model. Sorptivity values were much lower for sample B because of the smaller change in initial and saturated moisture contents.

\section{CONCLUSIONS}

The Philip model appeared to be most conservative estimate in this particular experiment based on the infiltration capacity curve. There was a sharp decline in infiltration, which is what would be expected, especially if the soil was initially dry but becomes wet over time. The Philip model also yielded results for the infiltration rate that approached the hydraulic conductivity for samples $B$ and $C$, suggesting that it may have been somewhat valid for that time interval. The Green-Ampt model works 
well for this kind of soil, but the variability in soil suction head leaves the results somewhat uncertain for this experiment. Since the Philip model was based on the Green-Ampt model's infiltration rates, this makes the Philip model uncertain as well. However, because the results are more conservative, it would be the best model on which to base conclusions about the infiltration rates.

Sample B had infiltration rates that were in typical ranges for loamy/sandy soils, and varied the least with a change in suction head and the wetting front length. This was likely due to the high initial moisture contents. If the initial moisture content is high, it will absorb less water, and the rate of water absorbed over time will not change as dramatically. Sample $A$ and $C$ had very low initial moisture contents which changed the infiltration rates and potentials for both models significantly. The field moisture contents may have been higher for sample $A$ and $C$ when first collected, but their sandier composition may have allowed the water to evaporate more easily than sample B. Since there was more organic matter in sample $B$, the organic material could hold on to its original moisture content for longer periods of time.

The results from this experiment provided estimates for the infiltration rates and infiltration potentials, but may not fully represent field conditions. By comparing the variables used and examining how the results change with changing variables, it is evident that the initial moisture content, the soil suction head, and the length of wetting front all change the results and how the results should be interpreted. The suction head for the Green-Ampt method should be measured because it is such a variable term for different soils, and there is no accurate way to predict what the suction head will be from soil to soil. The Philip model is more accurate if the infiltration rates are measured in the field, and data can be fit to the Philip model to estimate the sorptivity and gravity constant. Further tests should be done when using these models and a factor of safety should be applied to the hydraulic conductivity.

Without being able to perform a rainfall simulation, it is impossible to know which model worked best for which samples. To interpret conservative conclusions from these results, sample B should be the sample under examination since it had the lowest hydraulic conductivity and infiltration rate. The Philip model would be a more conservative estimate for this experiment since the infiltration capacity curve showed a steeper exponential decline. When the infiltration rate decreases rapidly, the overall infiltration capacity also decreases, so the Philip model would provide a more conservative estimate for infiltration potential as well. The infiltration capacity for sample B was $4.3 \mathrm{~cm}$, which was the lowest of all the samples between the Philip model and Green-Amp model. The infiltration rate at four hours was $0.77 \mathrm{~cm} / \mathrm{hr}$, which was also the lowest. This value is within typical ranges for sandy loam 
soils, which is likely the soil class for sample B. If a six year storm were to happen at the site, the soil bed would not be able to handle the precipitation and the stormwater flow from the roof at $9.8 \mathrm{~cm} / \mathrm{hr}$.

Due to the soil bed unable to handle the flow assuming a flattened soil bed, the capstone group will provide recommendations to the client for additional soil bed improvements. These improvements will include implementing a French drain along the length of the soil bed where the stormwater can flow with the gradient of the soil bed, parallel to the building, and underneath the parking lot. Vegetation will also be recommended to help stabilize the soil. A hearty plant species that would thrive and spread well in that area is kinnikinnick. Another recommendation for the client would be to line the sidewalk with bricks to prevent debris from being blown or washed onto the sidewalk. Infiltration modeling was a useful tool in evaluating the capacity of site soil to infiltrate precipitation from a 4-hour six year storm, and confirmed the need for these additional site improvement recommendations. 


\section{BIBLIOGRAPHY}

Clapp, R. B., Hornberger, G. M., (1978). "Empirical equation for some soil hydraulic properties." J. Water Resource Research, 14(4), 601-604.

Green, W. A., Ampt, G. A., (1911). "Studies on soils physics: 1. The flow of air and water through soils." J. Agricultural Science, 4, 1-24.

Guideal, R., Bala, A. E., Ikpokonte, A. E., (2011). "Preliminary estimates of the hydraulic properties of the Quaternary Aquifer in N’Djamena Area, Chad Republic." J. Applied Sciences, 11, 542-548.

Gupta, R. S., (2008). Hydrology and Hydraulic Systems, 3rd Ed., Waveland Press, Long Grove, IL. Jaynes, R. A., Gifford, G. F., (1981). “An in-depth examination of the Philip equation for cataloging infiltration characteristics in rangeland environments." J. Range Management, 34(4), 285-296.

Khosravifar, A., personal communication, May 18, 2017.

Mazloom, H., Foladmand, H., (2013). "Evaluation and determination of the coefficients of infiltration models in Marvdasht regions, Fars province." Intern. J. Advanced Biological and Biomedical Research, 1(8), 822-829.

Mollerup, M., (2007). "Philip's infiltration equation for variable-head ponded infiltration." J. Hydrology, 347(1-2), 173-176.

Ojha, R., Corradini, C., Morbidelli, R., Govindaraju, R. S., (2017). “Effective saturated hydraulic conductivity for representing field-scale infiltration and surface soil moisture in heterogeneous unsaturated soils subjected to rainfall events." J. Water, 134(9), 1-17.

Philip, J. R., (1957). "The theory of infiltration: 4. Sorptivity and algebraic infiltration equations". J. Soil Science, 84, 257-264.

Putte, A. P., Covers, G., Leys, A., Langhans, C., Clymans, W., Diels, J., (2013). “Estimating the parameters of the Green-Ampt infiltration equation from rainfall simulation data: why simpler is better." J. Hydrology, 476, 332-334.

Sihag, P., Tiwari, N. K., Ranjan, S., (2017). "Estimation and inter-comparison on infiltration models." J. Water Science, <https://doi.org/10.1016/j.wsj.2017.03.001>.

Turner, E. R., (2006). “Comparison of infiltration equations and their field validation with rainfall simulation." Department of Biological Resources Engineering, University of Maryland. 
Warrick, A.W., Nielsen, D. R., (1980). Spatial variability of soil physical properties in the field. In:

Applications of Soil Physics. D. Hillel Ed., Academic Press, New York, NY 319-344.

Water Environment Federation, American Society of Civil Engineers, (1998). Urban Runoff Quality Management, ASCE Publication. 